\title{
Saprophytic Colonization of Citrus Twigs by Diaporthe citri and Factors Affecting Pycnidial Production and Conidial Survival
}

\author{
S. N. Mondal, University of Florida, Department of Plant Pathology, Citrus Research and Education Center, Lake \\ Alfred 33850; A. Vicent, Instituto Agroforestal Mediterráneo, Universidad Politécnica de Valencia, Valencia-46022, \\ Spain; R. F. Reis, São Paulo State University, São Paulo, Brazil; and L. W. Timmer, University of Florida, Citrus \\ Research and Education Center, Lake Alfred 33850
}

\begin{abstract}
Mondal, S. N., Vicent, A., Reis, R. F., and Timmer, L. W. 2007. Saprophytic colonization of citrus twigs by Diaporthe citri and factors affecting pycnidial production and conidial survival. Plant Dis. 91:387-392.

Melanose, caused by Diaporthe citri, produces reddish brown lesions on the fruit, leaves, and twigs of citrus trees, and greatly reduces the marketability of fresh fruit. Most of the inoculum is produced in pycnidia on dead twigs in the tree canopy, which exude large numbers of conidia in slimy masses. In this study, detached twigs inoculated with conidia were readily colonized and produced large numbers of pycnidia within 30 to 40 days when they were soaked 3 to $4 \mathrm{~h}$ on alternate days. Conidial production was measured by wetting twigs in a rain tower periodically and collecting the conidia in the runoff water. Production began after 80 days and continued for nearly 300 days. In other experiments, production of mature pycnidia on detached twigs was greatest at 94 to $100 \%$ relative humidity $(\mathrm{RH})$ and at $28^{\circ} \mathrm{C}$. Low $\mathrm{RH}$ and temperature, however, favored survival of conidia in exuded masses on twigs. In the field, colonization of detached twigs by $D$. citri was high in rainy season, moderate in spring and early fall, and minimal in late fall and winter. Twig colonization was positively related to the number of rain days and average temperature, but not to total rainfall. In another experiment, inoculated twigs placed in the tree canopy developed pycnidia and then produced conidial masses for about 200 days. D. citri is a serious pathogen, but a weak parasite, that survives primarily by colonization and reproduction on dead twigs.
\end{abstract}

Additional keywords: Phomopsis citri

Melanose produces brick red lesions on citrus fruit, twigs, and leaves that vary from individual spots to large tearstain and mudcake patterns on the fruit (16). The disease is caused by Diaporthe citri F.A. Wolf (anamorph: Phomopsis citri H. Fawc.). Melanose affects all citrus species, but grapefruit and lemons are the most susceptible. The disease occurs in most citrus-growing areas of the world. It is most severe in moist, subtropical regions, less severe in the humid tropics, and unimportant in arid areas. It usually does not affect tree growth or fruit yield, but can reduce profitability of the fresh-market fruit. In Florida, Timmer et al. (12) reported that a reduction of $10 \%$ in the percentage of fresh-market grapefruit by melanose caused a loss of $\$ 866$ per hectare. Since fruit prices in the 2005-2006 season were much higher than at the time of that study, losses would be even greater now.

Corresponding author: L. W. Timmer

E-mail: lwtimmer@ufl.edu

Accepted for publication 10 October 2006.

doi:10.1094/PDIS-91-4-0387

(C) 2007 The American Phytopathological Society
D. citri forms pycnidia and perithecia on dead twigs in the grove and does not sporulate on or survive well in living tissue $(8,9,16)$. The primary source of inoculum is conidia that are produced in masses that exude from pycnidia embedded in dead twigs and are washed down on leaves, twigs, and fruit by rain-splash. Ascospores are produced in perithecia in larger dead wood and dispersed by air. Although ascospores are not considered to be a major source of inoculum, they do play a significant role in long-distance dispersal (16). D. citri survives in living twigs and saprophytically colonizes the twigs when they die (4). The reproductive cycle of this fungus is from twig to twig, and the infection of fruit and leaves has no significance for reproduction (9). As the tree ages and dead twigs accumulate, more inoculum of $D$. citri is produced, increasing the severity of melanose in the grove (2). Alternate wetting and drying of the twigs induces pycnidial formation and maturation. Mondal et al. (4) found that moisture, temperature, twig size, and melanose severity were factors that influenced pycnidium production. Pycnidial production was maximized when severely affected, detached twigs 3 to $5 \mathrm{~mm}$ in diameter were dried, incubated at $28^{\circ} \mathrm{C}$, and soaked for 3 to $4 \mathrm{~h}$ three times weekly.
D. citri requires a minimum of 8 to $16 \mathrm{~h}$ of moisture for infection of citrus leaves, depending on the temperature (1). In Florida, infection of fruit by $D$. citri occurs from petal fall to midsummer (16), and the fruit becomes resistant to infection by early July. High rainfall and temperature with extended periods of wetness in June and July in Texas caused severe melanose on grapefruit, and fruit become resistant about the same time as they do in Florida (11). Removal of dead twigs can reduce the levels of infection (17), but fungicide applications are needed to obtain a high level of control (10). Programs using copper and QoI fungicides have been developed for varieties with different levels of susceptibility $(10,12)$. Fungicides are primarily protective and have little or no effect in reducing inoculum on dead twigs $(14,15)$.

Mechanical hedging and topping of citrus trees is a common practice in Florida to facilitate harvest, increase light penetration, and allow movement of farm equipment. These practices leave large amounts of dead limbs and twigs in the tree canopy. In our earlier study (4), we found that melanose-free twigs did not produce pycnidia of $D$. citri after they died and considered that such twigs would not be a source of inoculum. However, we did not consider the possibility of secondary, saprophytic colonization of dead twigs in that study. No studies have been conducted on the longevity of inoculum production from dead twigs or the ability of conidia to survive once they have exuded from the pycnidium.

In this study, we investigated saprophytic colonization of dead twigs under laboratory and field conditions. The duration of inoculum production and survival of conidia were studied under both conditions, and the effects of humidity and temperature on the survival and pathogenicity of conidia exuded from pycnidia were investigated. A preliminary report of this study has been published (6)

\section{MATERIALS AND METHODS}

Laboratory studies. Production of conidia. Isolates Ser-2-2, P-94, D-1, and JMP-2 collected from melanose-affected grapefruit trees (5) were grown on potato dextrose agar (PDA) for about 10 days. From these cultures, four agar plugs with 
mycelia, one from each isolate, were transferred to dishes containing five to seven segments of autoclaved grapefruit twigs about $2 \mathrm{~mm}$ in diameter and 2 to $3 \mathrm{~cm}$ in length embedded into PDA. The cultures were incubated for 45 to 50 days at $25^{\circ} \mathrm{C}$ and examined for pycnidial production. Pycnidia were produced on the embedded twigs after 6 to 7 weeks. Conidia were collected under a stereomicroscope with a sterile needle from masses exuded from pycnidia on twigs and suspended into sterile distilled water. Conidial concentration in the suspension was adjusted to $10^{5} \mathrm{co}-$ nidia per $\mathrm{ml}$ and used for inoculations.

Saprophytic colonization. To determine whether dead twigs could be colonized, 60 1-year-old healthy grapefruit twigs about 2 to $4 \mathrm{~mm}$ in diameter were collected from a mature grapefruit grove. Twigs were cut into 10-cm-long segments, air-dried for 7 to 10 days, and autoclaved. These twigs were then soaked in a conidial suspension of $10^{5}$ conidia per $\mathrm{ml}$ for about $12 \mathrm{~h}$ at $25^{\circ} \mathrm{C}$. Inoculated twigs were air-dried in mesh bags for 7 to 10 days in the laboratory. To induce pycnidial production, twigs were soaked for 3 to $4 \mathrm{~h}$ three times weekly on alternate days for 45 to 50 days according to the method of Mondal et al. (4). Pycnidia are embedded in the twig tissue and are not readily visible. Thus, to determine the number of mature pycnidia, twigs were placed in a moist chamber overnight to induce exudation of conidial masses to determine the extent of colonization and pycnidial production.

Conidial production from artificially inoculated twigs. In studies to determine the quantity and duration of conidial production, twigs artificially inoculated were prepared as above. A rain tower was constructed to measure the effect of simulated rain on pycnidial development and conidial production. The rain tower was a box 75 $\mathrm{cm}$ high and $30 \mathrm{~cm}$ wide and built with 2mm-thick Plexiglas. The top was fitted with a $30 \times 30 \mathrm{~cm}$ plate with a spray nozzle at the center and connected to a water source by rubber tubing. The twigs were placed onto a $25 \times 25 \mathrm{~cm}$ wire mesh platform located $35 \mathrm{~cm}$ below the nozzle. The bottom portion of the tower was fitted with another bowed glass plate to channel the liquid into a beaker. Water pressure was adjusted to produce 1.2 liters/min of simulated rain sprayed uniformly over the twigs. Twigs were sprayed for $10 \mathrm{~s}$ four times a day at 2-h intervals once a week for 10 months. The concentration of conidia in the water was determined using hemacytometer and expressed as conidia per twig. Pathogenicity of conidia was tested on five grapefruit seedlings. Conidia $\left(10^{5}\right.$ per $\left.\mathrm{ml}\right)$ were sprayed on young shoots of grapefruit according to the method of Agostini et al. (1). Inoculated seedlings were covered with plastic bags and placed in the mist bed at ambient temperature (18 to $25^{\circ} \mathrm{C}$ ) and light conditions for $16 \mathrm{~h}$, then moved to the greenhouse for symptom development. The experiment was conducted twice and the average values for the two experiments are presented.

Effect of relative humidity and temperature on the production of conidial masses. To determine the effect of relative humidity on production of conidial masses from pycnidia on twigs, closed desiccators were set up with salt and sucrose solutions to create different relative humidities. Saturated solutions of $\mathrm{NaNO}_{3}$, sucrose, $\mathrm{KNO}_{3}$, $\mathrm{KH}_{2} \mathrm{PO}_{4}$, and distilled water were used to create relative humidities of 74.0, 85.0, 92.5, 96.0, and 100\%, respectively (7). Humidities in the chambers were verified using a Ratio Signal Remote Thermometer (Fisher Scientific, Pittsburgh, PA). Chambers were maintained at $25^{\circ} \mathrm{C}$. Air-dried twigs with mature pycnidia were placed inside chambers adjusted to the different humidities for 36 to $48 \mathrm{~h}$. To determine the effect of temperature on the production of conidial masses, plastic moist chambers were placed in incubators at 5, 20, 24, 28, and $32^{\circ} \mathrm{C}$. Air-dried twigs with mature twigs were placed in the moist chambers for 36 to $48 \mathrm{~h}$. The twigs in both studies were rated under a stereomicroscope, and density of pycnidia exuding conidial masses was rated on a 0 to 5 scale, where 0 $=$ none, $1=1$ to $50,2=51$ to $100,3=101$ to $150,4=151$ to 200 , and $5=>200$ pycnidia. The data presented are the average of the 15 twigs per treatment for the relative humidity experiment and 30 for the temperature treatments. In each case, two experiments were conducted.

Effect of humidity on viability and pathogenicity of conidia. In this study, 50 to 60 twigs with recently matured pycnidia with exuded conidial masses were placed inside the desiccators adjusted to the same humidities described above. Eight twigs were placed in each chamber for 50 to 60 days. Five to seven conidial masses were retrieved arbitrarily from the twigs biweekly using a fine needle and placed in 1$\mathrm{ml}$ of sterile distilled water. Suspensions were diluted to 2,000 conidia per $\mathrm{ml}$, and $0.1 \mathrm{ml}$ was spread onto acid PDA (1.6 $\mathrm{g}$ of tartaric acid per liter of PDA) and incubated for 3 to 5 days at $25^{\circ} \mathrm{C}$ and the colonies counted and expressed as the percentage of the total conidia applied. The pathogenicity of conidia was determined on detached young grapefruit leaves. Young leaves, from one-half to two-thirds of full expansion, were collected from greenhouse-grown grapefruit seedlings, disinfested for $2 \mathrm{~min}$ in $0.5 \%$ sodium hypochlorite and $2 \mathrm{~min}$ in $70 \%$ ethanol, and rinsed three times in sterile distilled water. Leaves were blotted dry and placed abaxial side up on plates of $1.5 \%$ water agar. Six $10-\mu l$ droplets of a conidial suspension (3 $\times 10^{5}$ conidia per $\mathrm{ml}$ ) were placed on each leaf. For each test, two petri dishes with six leaves were inoculated. In one dish, four leaves were mock-inoculated with droplets of sterile, deionized water as a control. Disease symptoms were rated using a 0 to 3 scale, where $0=$ no discoloration or pustule appearance, $1=$ mild, 2 $=$ moderate, and $3=$ severe discoloration and pustule development. The data presented are averages of six inoculated leaves. The two experiments are presented separately since the variances of the two experiments were not homogeneous.

Effect of temperature on viability and pathogenicity of conidia. Fifteen twigs with mature pycnidia with conidial masses were placed in incubators at 5,20,24, 28, and $32^{\circ} \mathrm{C}$ for 60 days. The ambient relative humidities in the incubators as measured using a hygrothermograph (Spectrum Technologies, Plainfield, IL) were approximately $12 \%$ at $5^{\circ} \mathrm{C}, 42 \%$ at $20^{\circ} \mathrm{C}, 64 \%$ at $24^{\circ} \mathrm{C}$, $71 \%$ at $28^{\circ} \mathrm{C}$, and $91 \%$ at $32^{\circ} \mathrm{C}$. Conidial survival and pathogenicity to grapefruit leaves were determined as described above. The data presented are the average of 15 twigs and two experiments.

Field studies. Colonization of twigs. Disease-free grapefruit twigs about 3 to 4 $\mathrm{mm}$ in diameter were cut into 10 -cm-long segments, air-dried for 7 days, autoclaved, and placed into mesh bags. The bags were placed in the canopy of grapefruit trees in a grove near Lake Alfred, FL, at monthly intervals for 2 years from January 2004 to December 2005. Each monthly sample consisted of three bags with 10 twigs each. At the end of each month, bags were returned to the laboratory and soaked 3 to 4 $\mathrm{h}$, three times a week on alternate days for 45 to 50 days to induce formation and maturation of pycnidia. The twigs were placed in the moist chambers for 24 to 36 $\mathrm{h}$ to observe conidial mass formation. The numbers of twigs producing conidial masses were counted and expressed as percentage of twigs colonized by $D$. citri. Pathogenicity of conidia produced in the masses was tested on detached young grapefruit leaves as described above. The number of rain days (days with more than $0.25 \mathrm{~mm}$ of rain), total rainfall, and average temperature data were retrieved from a weather station located about $500 \mathrm{~m}$ from the experimental site.

Production of conidial masses on artificially inoculated twigs. Mesh bags $(20 \times$ $20 \mathrm{~cm}$ ) containing 10 artificially inoculated twigs of grapefruit with mature pycnidia were air-dried in the laboratory and placed in the tree canopy of grapefruit to determine the duration of conidial mass production on the colonized dead twigs. Three bags of 10 twigs each were collected for evaluation once a month for 8 to 10 months. Twigs were placed in the moist chambers as described above to observe production of conidial masses and were rated under a stereomicroscope using the 0 to 5 scale described above. The experiment was conducted once from December 2004 to August 2005 and repeated from May 2005 to December 2005. 
Experimental design and data analysis. All the experiments were conducted at least twice. Data from the two studies were pooled for presentation in most instances since the variances of final outputs were homogeneous according to Bartlett's twotailed $F$ test, $P \leq 0.05$. Regression analyses were used to determine relationships between factors in some experiments. In those instances, curve-fitting was employed to determine nature of the relationships using the means of the two experiments. All analyses were conducted using SAS Version 8.2 (SAS Institute, Cary, NC).

\section{RESULTS}

Laboratory studies. Saprophytic colonization. Inoculation of autoclaved dead grapefruit twigs with conidia of $D$. citri resulted in colonization of all of the twigs. All 60 colonized twigs produced abundant pycnidia after they were soaked for $3 \mathrm{~h}$ on alternate days three times a week for 40 to 50 days.

Conidial production on artificially inoculated twigs. The inoculated twigs exposed to the rain tower conditions beginning immediately after inoculation began to produce conidia after 80 days and reached a peak after 100 to 120 days after inoculation (Fig. 1). Peak production continued for about 30 to 40 days, then declined, and production essentially ceased by 280 to 300 days. Total conidial production on saprophytically colonized twigs was estimated to be about $3.5 \times 10^{9} \mathrm{co}-$ nidia per twig. The conidia produced in pycnidia on colonized twigs were highly pathogenic to grapefruit leaves on all assay dates.

Relative humidity and temperature effects on production of conidial masses. There was a significant positive linear relationship between the density rating of conidial masses produced from artificially inoculated twigs and relative humidity (Fig. 2A). Conidial exudation from pycnidia on twigs was highest at 96 to $100 \%$ relative humidity (RH) after 36 to 48 $\mathrm{h}$, and virtually no conidial masses were produced at $50 \% \mathrm{RH}$. Exudation of conidia was greatest at $28^{\circ} \mathrm{C}$ and lower at 20,24 , and $32^{\circ} \mathrm{C}$; exudation was minimal at $5^{\circ} \mathrm{C}$ (Fig. 2B).

Effects of humidity and temperature on the viability and pathogenicity of conidia. Conidia survived well on dead twigs at 50 and $70 \% \mathrm{RH}$, but then survival declined exponentially and was very low at 96 to $100 \%$ RH (Fig. 3A). Pathogenicity followed an exponential decline with increase in relative humidity (Fig. 3B).

Temperature had a significant effect $(P$ $<0.05)$ on the viability of conidia in masses on the dead twigs (Fig. 4). Conidia survived well at 5 and $20^{\circ} \mathrm{C}$, but survival declined exponentially at higher temperature (Fig. 4A). Pathogenicity declined in a pattern similar to survival (Fig. 4B), indicating that the conidia that survived were still pathogenic. The effect of temperature on survival was complicated by the differences in relative humidity in the different incubators, and survival at high tempera- tures may have been greater if humidities had been lower.

Field studies. Colonization of twigs. Autoclaved twigs placed monthly in the

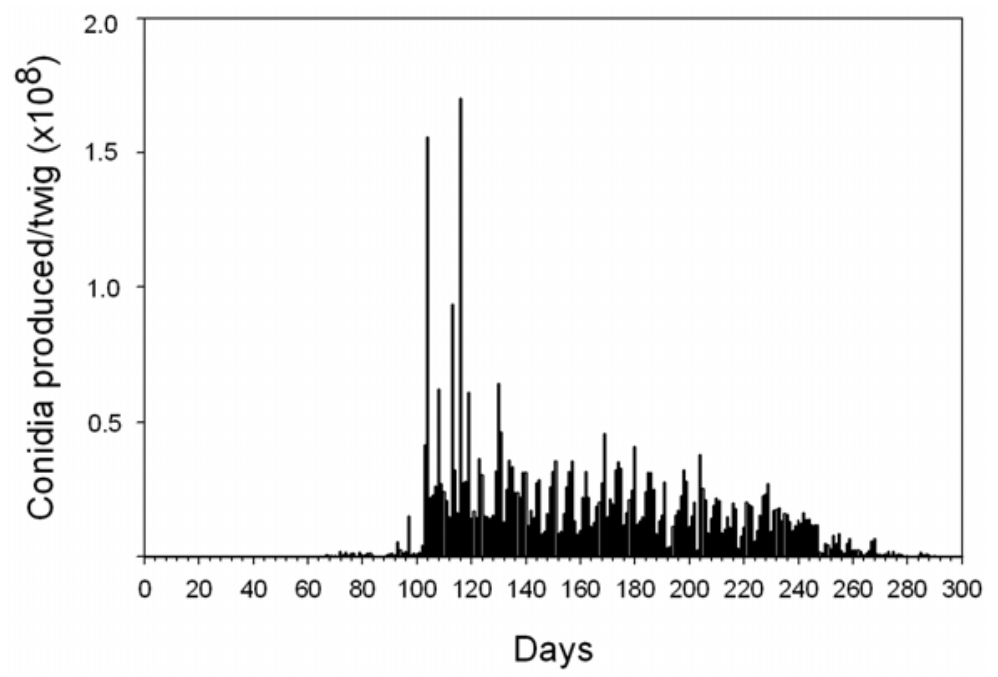

Fig. 1. Production of conidia of Diaporthe citri from artificially inoculated dead citrus twigs as measured in a rain splash chamber with time after inoculation. Average of two experiments.

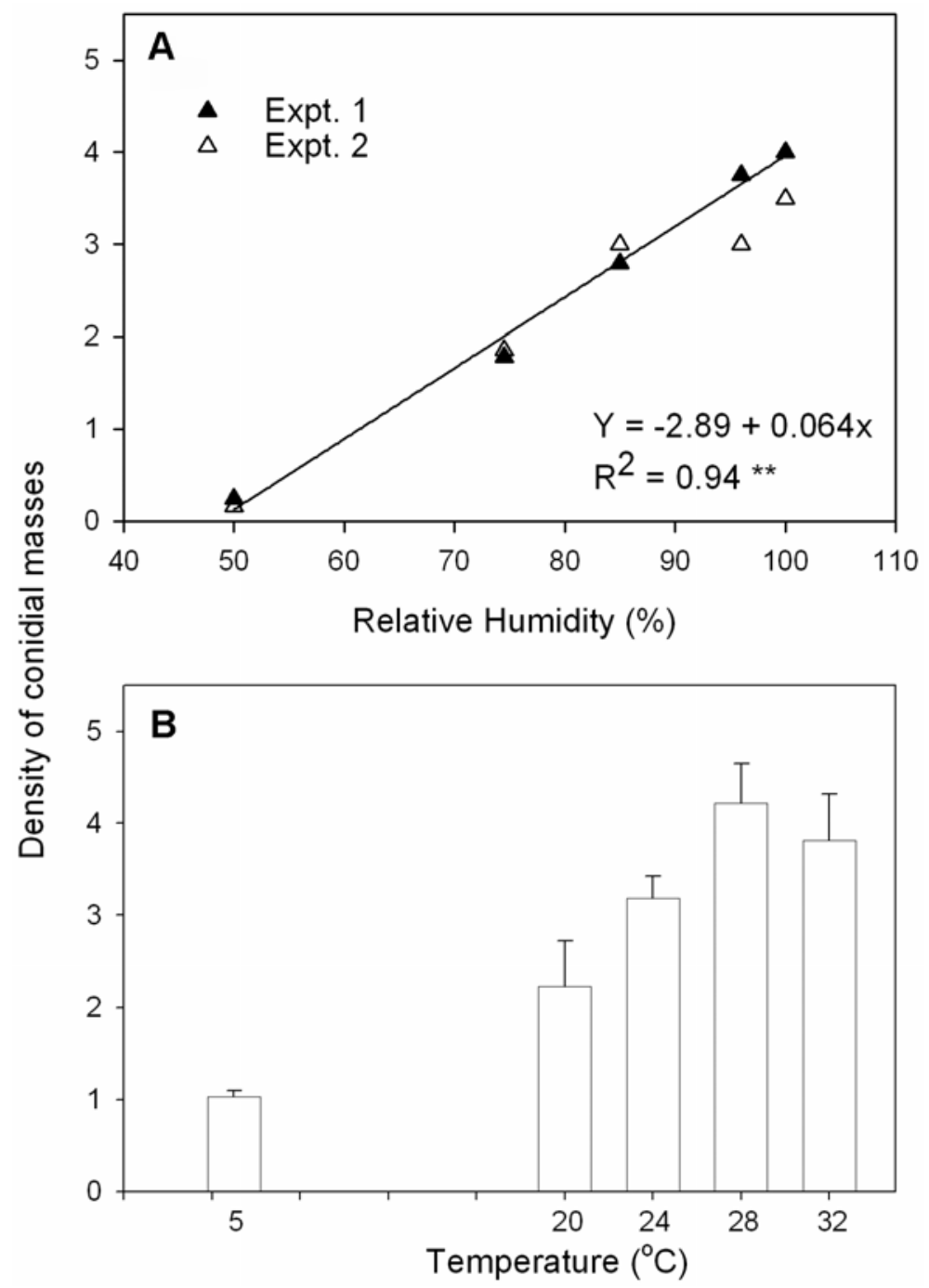

Fig. 2. Effect of $\mathbf{A}$, relative humidity and $\mathbf{B}$, temperature on the exudation of conidial masses of Diaporthe citri from mature pycnidia on artificially inoculated dead citrus twigs. Average of two experiments. 

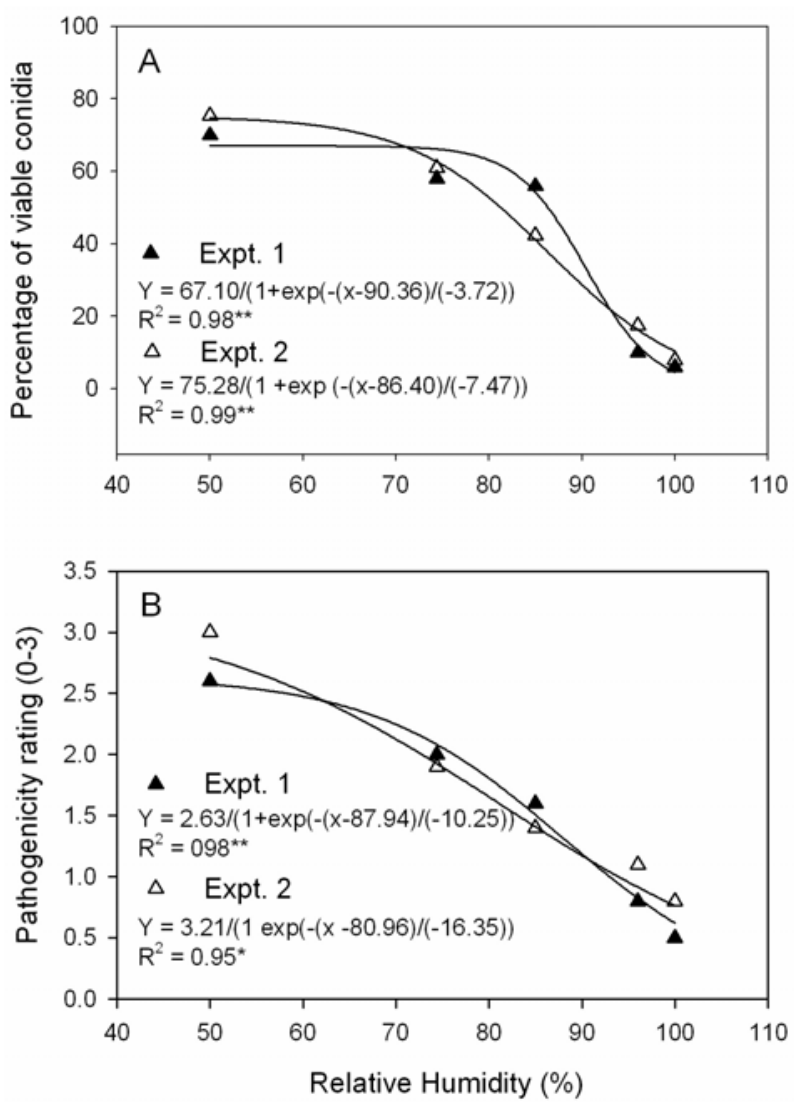

Fig. 3. Effect of relative humidity on $\mathbf{A}$, survival and $\mathbf{B}$, pathogenicity of conidia of Diaporthe citri in masses that had exuded onto the surface of artificially inoculated citrus twigs after 60 days. Variances of the two experiments were not homogeneous, and results of each are presented separately.
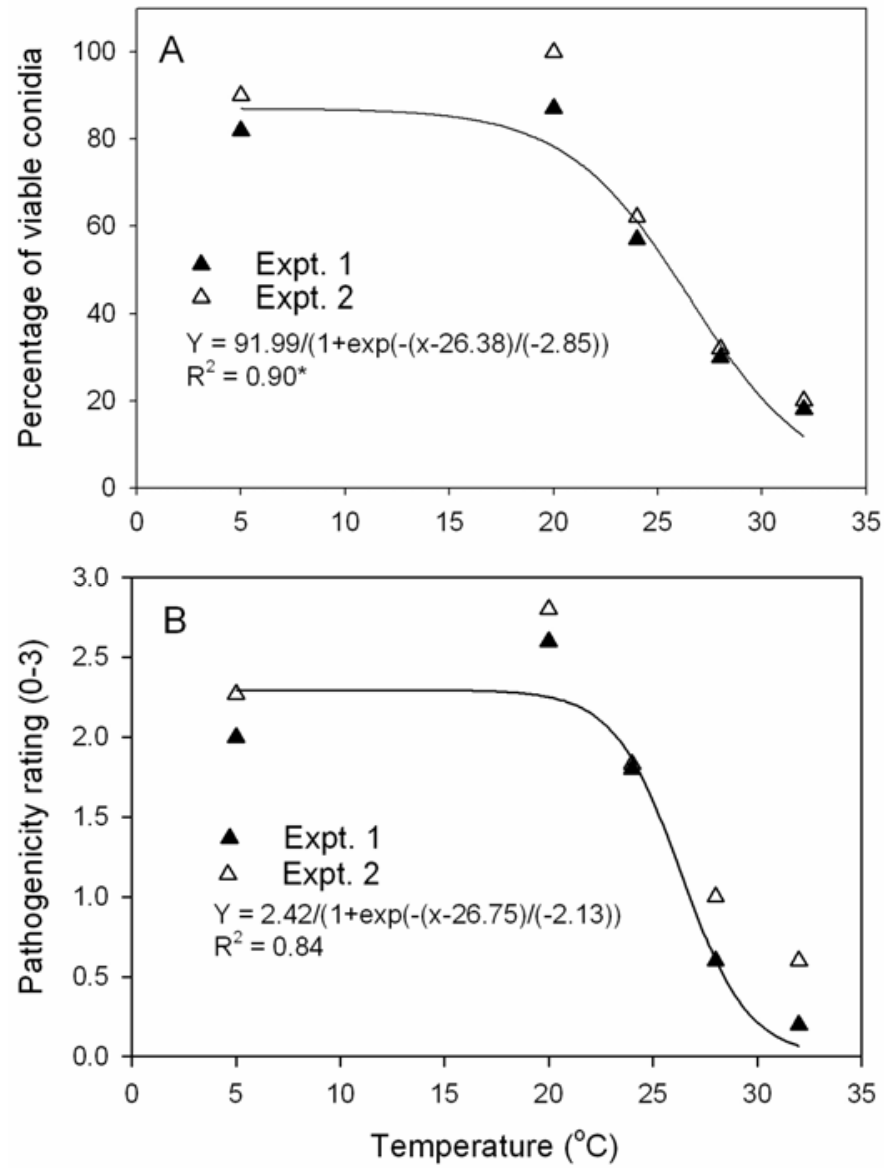

Fig. 4. Effect of temperature on A, survival and $\mathbf{B}$, pathogenicity of conidia of Diaporthe citri in masses that had exuded onto the surface of artificially inoculated citrus twigs after 60 days. Average of two experiments. tree canopy in grapefruit grove were colonized by $D$. citri to some extent in every month of the year (Fig. 5). The pattern of colonization was similar in both years. Colonization was greatest in the early part of the rainy season in June and July, but declined later in the rainy season in August and September. A relatively low percentage of the twigs was colonized in the dry season from fall to late spring. The percentage of the twigs colonized was significantly related to the number of rain days and to average temperature, but not to total rainfall (Table 1). Stepwise multiple regression analyses were conducted, but colonization of twigs was no more related to any combination of weather factors than to any factor alone. Rainfall and temperature were often negatively correlated, complicating the interpretation of these factors.

Production of conidial masses. When colonized twigs were placed in the field at different times of the year, the number of pycnidia that produced conidial masses increased with time and peaked 3 to 4 months after placement and then declined (Fig. 6). In both experiments, some pycnidia remained viable for 8 to 10 months.

\section{DISCUSSION}

The majority of the inoculum of $D$. citri is produced on dead twigs in the canopy of the tree, and disease increases with increasing amounts of dead twigs in the tree $(2,4,16)$. In our earlier study $(4)$, we found that dead melanose-affected twigs produced mature pycnidia in about 45 days when wetted and dried three times a week. Production of pycnidia only occurred on melanose-affected twigs, and production increased as disease severity increased. Since many of the twigs removed by hedging and topping would be on the outside of the canopy, most would have low levels of infection. Thus, we concluded that the presence of melanose-free twigs that remained in the canopy following hedging and topping would not represent a high risk of infection. We also found that detached melanose-affected twigs placed in the canopy from January to April produced the greatest number of pycnidia. However, we did not consider the possibility of secondary saprophytic colonization of unaffected twigs that might be present in the trees.

In this study, detached twigs free of melanose were readily colonized in the laboratory, and detached melanose-free twigs placed in the field were colonized and produced large numbers of pycnidia, especially in the summertime. Thus, twigs remaining in the canopy after hedging and topping could become colonized and in- crease the inoculum supply. According to our previous study (4), melanose-affected twigs that die from January to April supply most of the inoculum for infection of fruit, which are susceptible from petal fall in April till the fruit become resistant in early July $(10,16)$. Since the spring season in Florida is relatively dry, most of the infection by $D$. citri on twigs and leaves occurs on the summer flush of growth. As found in the current study, that time also appears to be the most likely period that any dead, melanose-free twigs could be colonized by D. citri. However, twigs colonized during the summer rainy season would likely be decayed before the next fruit season (4) and would be an unlikely source of inoculum during the principal infection period for fruit. They could serve as a source of inoculum for late summer vegetative flushes and serve to perpetuate and increase disease levels in trees.

Few previous studies have been conducted on the factors affecting conidial production and survival of conidia produced in the slimy spore masses that exude from pycnidia on citrus or on other crops. With Phomopsis blight of red-cedar, Hodges and Green (3) found that conidia could survive on dead tissues for as long as 18 to 24 months. In the present study, we found that conidia are exuded onto the 


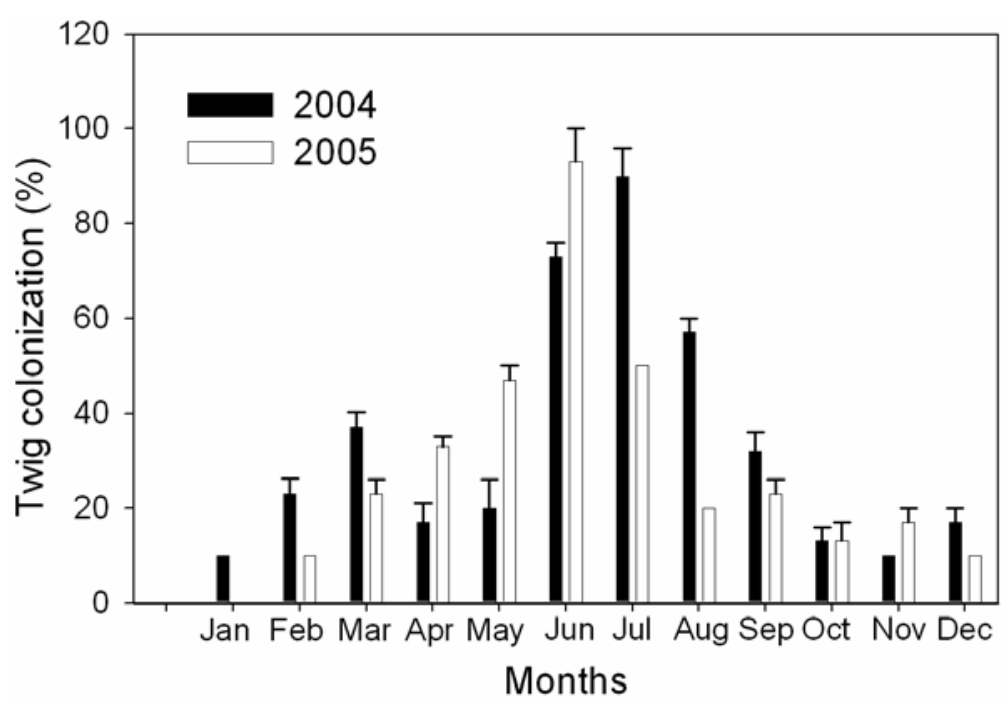

Fig. 5. Percentage of dead, sterilized citrus twigs placed in a citrus tree canopy at monthly intervals that were colonized by Diaporthe citri. Bars equal SE of the means.

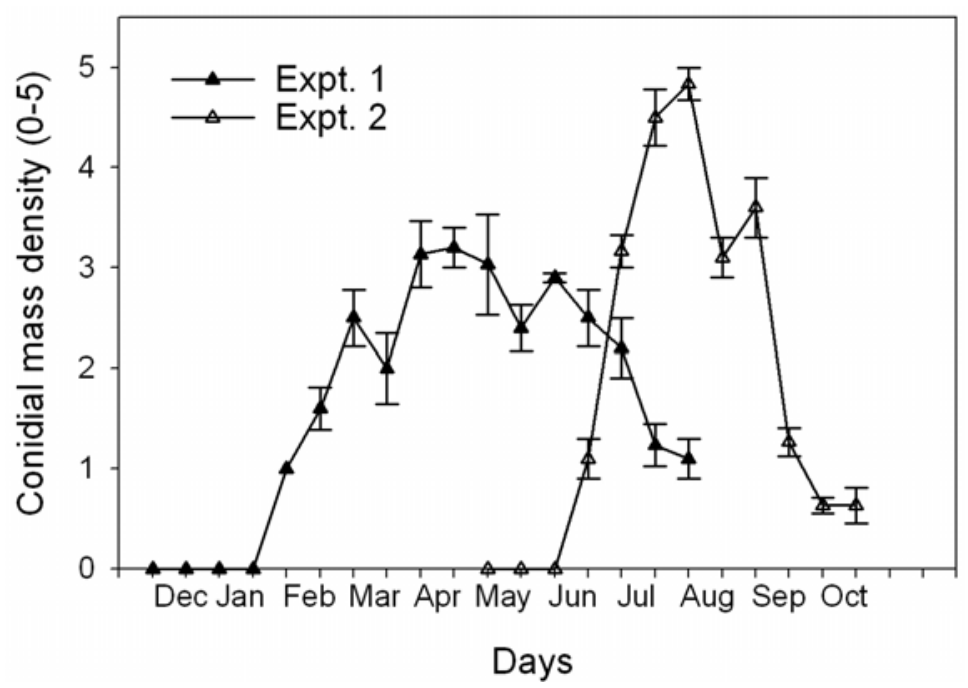

Fig. 6. Density of conidial masses formed on dead citrus twigs artificially inoculated with Diaporthe citri after various periods of time following their placement in the tree canopy in the field. Experiment 1 was conducted from December 2004 to October 2005 and experiment 2 from May 2005 to April 2006. Bars equal SE of the means.

surface of the twigs not only when it rains but also during periods of high humidity. Conidia are exuded as spore tendrils (16) under conditions of low humidity and as slimy masses at high humidity. The viability of conidia exuded and maintained under humid conditions is shorter than for conidia exuded and maintained under drier conditions. Thus, conidia produced in the rainy summer season would have to be dispersed soon after exudation to be infectious. However, conidia exuded under drier and cooler conditions in late fall and winter would likely remain viable for extended periods. It appears from our results that as long as conidia remain viable, they are still pathogenic as well.

D. citri is a serious pathogen of citrus causing severe blemishing of fruit that reduces its value for the fresh market. However, this fungus is a weak parasite on
Table 1. Linear regression analysis of the relationship of rainfall and temperature to the percentage of detached grapefruit twigs that were colonized by Diaporthe citri after placement in the tree canopy ${ }^{\mathrm{a}}$

\begin{tabular}{lcc}
\hline Weather factors & $\begin{array}{c}\mathbf{2 0 0 4} \\
\boldsymbol{R}^{\mathbf{2}}\end{array}$ & $\begin{array}{c}\mathbf{2 0 0 5} \\
\boldsymbol{R}^{\mathbf{2}}\end{array}$ \\
\hline Rain days/month & $0.34 *$ & $0.51 * *$ \\
$\begin{array}{l}\text { Rainfall (total/month) } \\
\text { Average monthly }\end{array}$ & $0.23 \mathrm{~ns}$ & $0.14 \mathrm{~ns}$ \\
$\quad$ & $0.46 * *$ & $0.59 * *$ \\
\hline
\end{tabular}

${ }^{a}$ Healthy detached autoclaved twigs $10 \mathrm{~cm}$ long and 2 to $4 \mathrm{~mm}$ in diameter were placed in the tree canopy monthly from January 2004 to December 2005. * and $* *=$ significant at $P \leq$ 0.05 and 0.01 , respectively. ns $=$ not significant.

such as shading or injury. Removal of dead twigs can eliminate some inoculum and reduce disease on citrus (17) as with other Phomopsis diseases on crops such as peach (13) and red-cedar (3), but physical removal of dead twigs from citrus trees would not be economical under current conditions. Twig death can be minimized by maintaining good fertilization and cultural practices, controlling pests and diseases, and mechanical topping of trees to remove some inoculum and to allow better sunlight penetration.

\section{LITERATURE CITED}

1. Agostini, J. P., Bushong, P. M., Bhatia, A., and Timmer, L. W. 2003. Effects of environmental factors on the severity of citrus scab and melanose. Plant Dis. 87:69-74.

2. Davis, R. M., and Wilhite, H. S. 1983. Relationships between melanose incidence and dead wood in Texas grapefruit. J. Rio Grande Valley Hortic. Soc. 36:41-49.

3. Hodges, C. S., and Green, R. J. 1961. Survival in the plantation of eastern redcedar seedlings infected with Phomopsis blight in the nursery. Plant Dis. Rep. 45:134-136.

4. Mondal, S. N., Agostini, J. P., and Timmer, L. W. 2004. Factors affecting pycnidial development of Diaporthe citri, the cause of citrus melanose. Plant Dis. 88:379-382.

5. Mondal, S. N., Bhatia, A., Shilts, T., and Timmer, L. W. 2005. Baseline sensitivities of fungal pathogens of fruit and foliage of citrus to azoxystrobin, pyraclostrobin, and fenbuconazole. Plant Dis. 89:1186-1194.

6. Mondal, S. N., and Timmer, L. W. 2005. Saprophytic colonization, pycnidial production, and conidial survival on dead twigs by $D i$ aporthe citri, the cause of citrus melanose. (Abstr.) Phytopathology 95:S71.

7. Reis, R. F., de Goes, A., Mondal, S. N., Shilts, T., Brentu, F. C., and Timmer, L. W. 2006. Effect of lesion age, humidity, and fungicide application on sporulation of Alternaria alternata, the cause of brown spot of tangerine. Plant Dis. 90:1051-1054.

8. Ruehle, G. D., and Kuntz, W. A. 1940 Melanose of citrus and its commercial control Fla. Agric. Exp. Stn. Bull. 349. University of Florida, Gainesville.

9. Timmer, L. W. 1999. Diseases of fruit and foliage. Pages 107-115 in: Citrus Health Management. L. W. Timmer and L. W. Duncan, eds. American Phytopathological Society, St. Paul, MN.

10. Timmer, L. W., and Chung, K.-R. 2006 Melanose. Pages 83-84 in: The 2006 Florida Citrus Pest Management Guide. M. E. Rogers 
and L. W. Timmer, eds. Univ. Fla. Coop. Ext. Serv., University of Florida, Gainesville. Publ. No. SP-43.

11. Timmer, L. W., and Fucik, J. E. 1976. The relationship of rainfall distribution, fruit growth and fungicide application to the incidence of melanose of grapefruit in Texas. Plant Dis. Rep. 60:565-568.

12. Timmer, L. W., Zitko, S. E., and Albrigo, L. G. 1998. Split application of copper fungicides improve control of melanose on grapefruit in Florida. Plant Dis. 82:983-986.

13. Uddin, W., and Stevenson, K. L. 1998. Seasonal development of Phomopsis shoot blight of peach and effects of selective pruning and shoot debris management. Plant Dis. 82:565-568.

14. Whiteside, J. O. 1977. Sites of action of fungicides in the control of citrus melanose. Phytopathology 67:1067-1072.

15. Whiteside, J. O. 1980. Timing of fungicide spray treatments for citrus melanose control. Proc. Fla. State Hortic. Soc. 93:21-24.

16. Whiteside, J. O. 2000. Melanose. Pages 28-29 in: Compendium of Citrus Diseases. L. W. Timmer, S. M. Garnsey, and J. H. Graham eds. American Phytopathological Society, St. Paul, MN.

17. Winston, J. R., Bowman, J. J., and Bach, W. T. 1927. Citrus melanose and its control. U.S Dep. Agric. Bull. 1474. 